- Revista de Iniciação à Docência, v. 5, n. 1, 2020 -

Dossiê Temático: Docência Universitária: contribuições da pesquisa Publicação: maio, 2020 - ISSN 2525-4332

\title{
A ARTE DO SENSÍVEL NA DOCÊNCIA UNIVERSITÁRIA: NARRATIVAS POÉTICAS ACERCA DO BRINCAR DE ESTUDANTES DE PEDAGOGIA
}

Marilete Calegari Cardoso ${ }^{1}$

RESUMO: O estudo aponta as narrativas experipoiéticas como um caminho alternativo para a uma didática lúdica docente e como uma forma de aprendizagens das dimensões sensíveis no ensino superior. Analisa as experiências de estudantes do curso Licenciatura em Pedagogia de uma universidade pública da Bahia, acerca do brincar de crianças. Trata-se de uma pesquisa qualitativa, uma experiência de formação sensível, embasada numa concepção orgânica e estética, mediada por narrativas em forma de poesias e relatos escritos. As análises descritivas foram ancoradas na fenomenologia compreensiva de Michel Maffesoli. Os principais resultados demonstram que: a) os sentidos produzidos pelas graduandas, mediado pelas narrativas experipoiéticas, podem ser reconhecidos como uma formação sensível e de aprendizagem significativa; b) as narrativas das estudantes, em forma de poemas, alteram os experiências/sentidos produzidos acerca do brincar, desse modo, destacamos o papel da arte na docência universitária aguçando a sensibilidade na formação humana.

Palavras-Chave: Lúdico; Narrativas Experipoiéticas; Pedagogia; Sensibilidade.

\section{Introdução}

A complexidade da docência universitária, ao longo das últimas duas décadas, vem sendo objeto de iniciativas e de estudos difundidos na academia. Alimenta-se, a necessidade de repensar as formas de ensinar e aprender dos docentes, quando a universidade, como campo de produção científica, vive um momento de mudança de paradigma, na qual percebe-se uma saturação do valor do trabalho, e, busca-se, hoje, uma expansão da ideia de criação e criatividade (MAFFESOLI, 2011).

A docência tem a marca das relações humanas, portanto é atividade interativa, dialógica, sensível e lúdica, na qual as diversas linguagens se fazem mais atuantes e significativas na aprendizagem e desenvolvimento do alunado. Porém, continuam sob pauta de investigação várias problemáticas, sobretudo aquelas que se ancoram no conhecimento e reflexão acerca da formação docente, da relação teoria e prática, da estética, da mediação didática, da arte de aprender e ensinar.

$\mathrm{Na}$ universidade a dimensão lúdica vem sendo defendida como um elemento estruturador para a formação de professores (LEAL; D’ÁVILA, 2013; FORTUNA, 2012; LUCKESI, 2014). Partindo da premissa que uma docência de qualidade em espaços formais, supõe uma atitude cotidiana de olhar atento aos diferentes tempos, lugares e sujeitos, as possibilidades de experiências formativas transversais ao academicismo dão sinais de vida, tornando concreta uma formação norteada pela sensibilidade, criatividade e reflexão. Porém, percebe-se um problema desafiador e essencial para docência universitária: pensar

\footnotetext{
1 Doutora em Educação (UFBA). Mestre em Educação (UFBA). Pesquisadora do Grupo de Pesquisa em Educação, Didática e Ludicidade - GEPEL/UFBA. Professora Adjunta do Departamento de Ciências Humanas e Letras, Campus UESB, Jequié/BA. E-mail: marilete.cardoso@uesb.edu.br
} 
- Revista de Iniciação à Docência, v. 5, n. 1, 2020 -

Dossiê Temático: Docência Universitária: contribuições da pesquisa

Publicação: maio, 2020 - ISSN 2525-4332

caminhos que fomentem a expressão do saber e o modo de olhar para a dimensão lúdica na formação do professor.

Efetivamente, abrem-se lacunas para se repensar caminhos para metodologias ativas construídas e/ou vividas no ensino superior, que tem como desafio formar profissionais considerando a diferença e a diversidade, assim como abrir espaço para as dimensões sensíveis, mediadas por uma didática lúdica. Assim como, emerge a necessidade de construirmos uma sólida pesquisa que permita o diálogo e a reflexão sob novas possibilidades didáticas e investigações sobre o ensino como prática social viva (PIMENTA, 2013).

A sensibilidade é forma aberta (intuitiva, imaginária, analógica, lúdica, autopoética), de ser, viver, compartilhar, dialogar e relacionar a tudo o que vive e existe com significação. Por isso, a dimensão sensível pode ser um caminho aberto para a produção de sentido/experiência, como ressalta Maffesoli (2005), "que bem poderia ser a marca da pósmodernidade" (p. 16), a qual tem sido reconhecida como uma emergência da experiência de vida e como compreensão das realidades humanas.

As Diretrizes Curriculares Nacionais para a Formação Inicial e Continuada dos Profissionais do Magistério da Educação Básica (BRASIL, 2015, p. 29)² abrem caminhos para pensarmos em propostas formativas lúdicas para os cursos de licenciaturas. No seu Art. $7^{\circ}$, essas diretrizes propõem que as experiências de formação de profissionais sejam compostas pela pluralidade de conhecimentos teóricos e práticos, resultado de um percurso formativo vivenciado, cuja consolidação virá do seu exercício profissional, fundamentado em princípios de interdisciplinaridade, contextualização, democratização, pertinência e relevância social, ética e sensibilidade afetiva e estética, de modo a lhe permitir:

[...] conhecimento multidimensional e interdisciplinar sobre o ser humano e práticas educativas, incluindo conhecimento de processos de desenvolvimento de crianças, adolescentes, jovens e adultos; [...] questões atinentes à ética, estética e ludicidade no contexto do exercício profissional, articulando o saber acadêmico, a pesquisa, a extensão e a prática educativa (BRASIL, 2015, p. 27-29).

Mas, afinal, quais os caminhos para uma educação orgânica, valorizadora do conhecimento sensível, lúdico, estético e cultural na formação inicial e contínua de professores? Como mediar a aprendizagem de estudantes do curso Licenciatura em Pedagogia, na produção de experiências/sentidos para/com o lúdico na educação superior?

Apoiado na pesquisa realizada por Cardoso (2018), este artigo discute os aportes teóricos das narrativas experipoiéticas - uma junção das palavras experiência e poiética, significando uma forma experimental de metaforizar o que se vê e se sente ao observar, contemplar ou relembrar um lugar ou uma cena -, como um caminho alternativo à prática docente universitária e como uma forma de aprendizagens das dimensões sensíveis no

\footnotetext{
${ }^{2}$ Resolução CNE (002/2015), recentemente revogada e substituída pela Resolução CNE (002/2019).
} 
- Revista de Iniciação à Docência, v. 5, n. 1, 2020 -

Dossiê Temático: Docência Universitária: contribuições da pesquisa Publicação: maio, 2020 - ISSN 2525-4332

ensino superior. Analisa as experiências/sentidos de estudantes do curso Licenciatura em Pedagogia, de uma universidade pública da Bahia, acerca do brincar de crianças.

\section{Mirando o olhar às narrativas experipoiéticas na educação universitária}

As dimensões sensíveis têm sido apontadas como a chave para uma docência universitária que privilegie o ensino como prática social viva, sob o ponto de vista do paradigma orgânico e estético, como vem sendo abordado por autores como Michel Maffesoli (1988; 2005) e D’Ávila e Ferreira (2018) entre outros. Trata-se de uma sensibilidade que desperte às possibilidades da ética e da estética, em que o lúdico, a poesia, a imaginação e as narrativas de experiências, vem sendo apontadas como um fenômeno da formação, e reconhecidas de forma significativa e relacional, sobretudo, na desconstrução e produção de novos sentidos.

A prática docente com as dimensões sensíveis, como as metáforas criativas, as poesias e as experiências/sentidos no campo de trabalho - vêm acompanhando as ideias de pensadores contemporâneos (DEWEY, 2010; MAFFESOLI, 1988; 2005; MORIN, 2005; SANTOS, 2003; NÓVOA, 1997; 2002), que consideram a prevalência das relações cotidianas, como caminho para uma educação integral do ser humano. Conforme Santos (2003, p. 72) assinala, as analogias lúdica, dramática e biográfica constituem-se em formas emergentes para tentarmos romper com nossa visão compartimentalizada de mundo. Essas formas são caminhos que "revelam senso comum, para se aproximar das realidades terrenas contra as quais, em tempos, o discurso científico procurou-se edificar-se" (NÓVOA, 1997, p. 32). E que, portanto, trazem o diálogo em prol de um movimento "orgânico e intencional de educação e formação de seus profissionais" (PIMENTA, 2014).

Maffesoli (2005) compreende as dimensões sensíveis (poesias, metáforas, ludismo), como caminhos abertos para uma formação global e concreta, apostando em um "paradigma estético" que indica o espírito de vibrar e sentir em comum, tendo as emoções como vetor social. Conforme argumenta o autor, a estética, que vem do grego "aisthesis" - compreensão dos sentidos -, compõe-se de vivências que remetem à percepção e ao despertar de sensações, envolvendo todo o corpo, não apenas a visão, pois apesar de tangenciar o aspecto visual, não se limita a ele (FREITAS, 2014). Uma estética da recepção que repousa sobre a intuição, pois como já disse Galeffi (2007) “tudo o que vive é sensível de múltiplas maneiras" (p. 98).

Nesta perspectiva, D’Ávila e Ferreira (2018, p. 35-36), apontam a didática lúdica e sensível como elemento fundante da "Pedagogia Raciovitalista". De acordo com as autoras, essa formação aberta inclui "para além da inteligibilidade dos conhecimentos, o saber sensível (estésico), da arte (estético) e do lúdio (a graça e a plenitude)”, na qual apresenta um leque de saberes pedagógicos necessários à docência universitária, conforme procura ilustrar a Figura 1, proposta a seguir. 
Figura 1 - “Pedagogia Raciovitalista” (D’ÁVILA; FERREIRA, 2018).

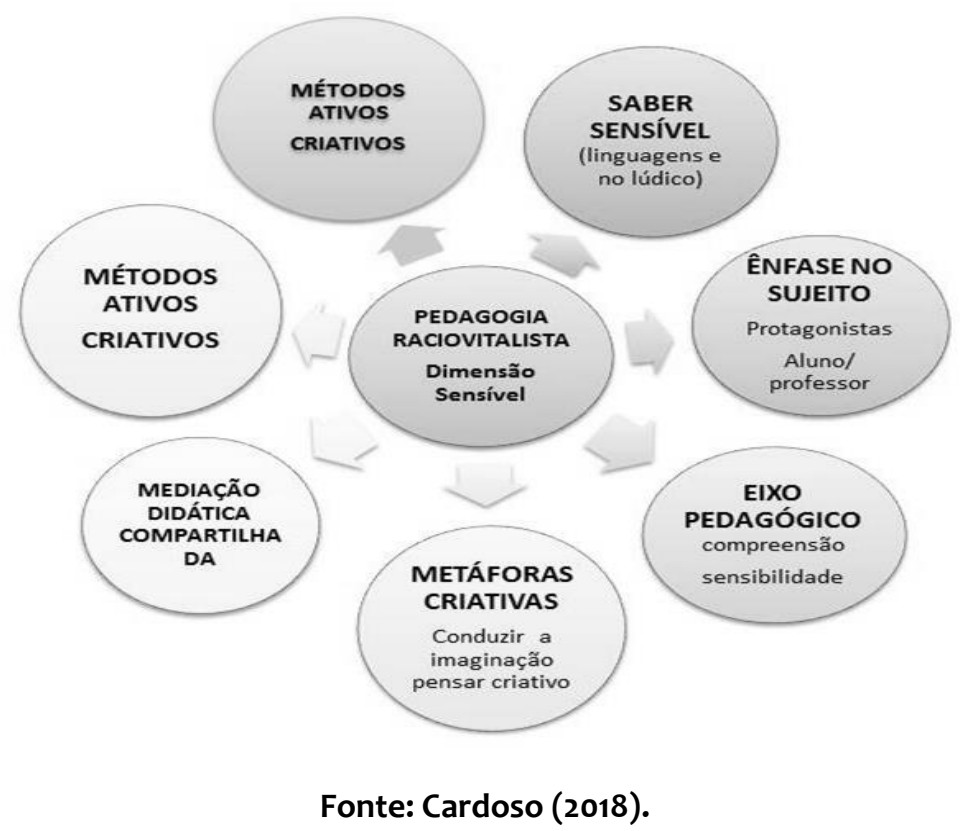

Para colocar em prática essas três dimensões de forma indissociável, o professor necessita orquestrar uma didática que permita primeiro a sensibilização, a metaforização; a criação de situações desafiadoras, a fim de que se possa mediar e interagir com os alunos de modo compartilhado (D' ÁVILA; FERREIRA, 2018). Ou seja, nesta experiência formativa sensível, busca-se por caminhos que o aluno possa produzir seus saberes por meio de narrativas, redescobrindo o sentir, o pensar e o agir, como uma potência poética e criativa.

Em pesquisa realizada com base nos pressupostos de $M$. Maffesoli e inspirada na poesia experimental portuguesa3 ${ }^{3}$, criamos o termo experipoiética - uma junção das palavras experiência e poiética, significando uma forma experimental na qual o sujeito se autoriza a exercer a capacidade de sentir e pensar sob o olhar autopoiético (CARDOSO, 2018). Este significado está embasado no conceito de poiési - "na ótica da estética, que concebe a arte como criação, conhecimento, ação prática e sensibilidade” (ABBAGNANO, 2000, p. 371).

A poesia assenta-se numa prática experimental. Prática que, segundo Barcelar (2001), "à primeira vista transmite um aspecto efémero, volátil, inconsistente, num interminável jogo de tentativa e erro" (p. 3). Uma experiência que está no território das artes, no campo da estética e que se constitui como um dos andaimes da poiésis.

A Poética, essa, instaura-se no campo da probabilidade, ou seja, da riqueza semântica da informação, manifesta-se pela novidade, confunde-se com a capacidade de dizer o que nunca foi dito antes e por isso tem as características do real absoluto: autogénico e inaugural. O dizer do poético é o dizer do tudo. [...] O

\footnotetext{
3 Segundo Torres (2008), a Poesia Experimental portuguesa surgiu com o experimentalismo poético português, marcado pela descoberta da poesia visual e concreta internacional, levando um grupo de poetas a escolherem a designação de Poesia Experimental para catalogar as suas atividades.
} 
- Revista de Iniciação à Docência, v. 5, n. 1, 2020 -

Dossiê Temático: Docência Universitária: contribuições da pesquisa Publicação: maio, 2020 - ISSN 2525-4332

ver do poético é o ver total. [...] Pensar por isso em Poesia é pensar na utopia do presente: a materialização, em códigos visuais comunicáveis, daquilo que é improvável e invisível: a comunicação. [...]. Mas, tornar visível o invisível e tornar possível o impossível, sempre foi essa a tarefa dos poetas (MELO; CASTRO, 1988, p. 14 apud BARCELAR, 2001, p. 7).

Entende-se que, a escrita em forma de poesia, ao libertar-se gradualmente da função inicial de puro registro de coisas ou fatos, descobre e desenvolve uma dimensão artística, acompanhando e contribuindo para a evolução das sociedades, refletindo a sua concepção do mundo: os seus gostos, modos de pensar, de comunicar e, sobretudo, da sua capacidade de inventar.

Entendendo que a metodologia lúdica aplicada nas disciplinas de graduação tem um peso grande, daí advém a necessidade da vivência de atividades lúdicas como ingrediente constante nas aulas. Seguindo essa perspectiva, as narrativas experipoiéticas constituemse em diferentes formas de brincar com a poesia e a arte. É uma prática experimental na produção de sentidos (que invoca uma sensibilidade), ao tornar visíveis as formas e forças de nossos sentidos, as experiências sensíveis que as constituem. Em outras palavras, tratase do interjogo entre a imaginação e a sensibilidade, dando forma e conhecimento para a construção de sentidos.

Acredita-se que as narrativas experipoiéticas são formas de metaforizar, criar modos de intervenção didática a partir de múltiplas linguagens artísticas e lúdicas (D’ÁVILA; FERREIRA, 2018), com a possibilidade de levantar as experiências significativas sobre o brincar de estudantes do Curso de Pedagogia. Crê-se, também, que são caminhos abertos com respectivos ecos na memória de suas vivências com o lúdico. Essas experiências contribuem para o desenvolvimento, transformação e consolidação de compreensões em relação aos sentidos do brincar à profissionalidade, com isso, ressignificam seus saberes pedagógicos do dia a dia.

\section{Opções metodológicas: trilhas de uma pesquisa formativa}

Com o objetivo de compreender os sentidos construídos por estudantes do Curso de Pedagogia acerca do brincar das crianças, desenvolveu-se um estudo qualitativo, embasado na fenomenologia compreensiva de Maffesoli (1988; 2005). Com isso, utilizouse o método pesquisa formação (MACEDO, 2009), atrelado ao método (auto)biográfico (NÓVOA, 2002), e a didática sensível (D’ ÁVILA; FERREIRA, 2018), articulada ao trabalho realizado no Projeto "Baú Brincante"4 - um projeto colaborativo entre escola e universidade.

\footnotetext{
${ }^{4} \mathrm{O}$ projeto Baú Brincante foi pesquisa realizada durante o período de agosto 2016 até dezembro 2017, sob a coordenação geral da Prof. ${ }^{a}$ Cristina d'Ávila, envolvendo a Universidade do Estado da Bahia - UNEB e a UESB, em duas escolas, nas cidades de Salvador e Jequié. Esse estudo nasceu da parceria do Grupo de Pesquisa em Educação e Ludicidade — GEPEL, da UFBA, em cooperação entre o Programa de Pós-Graduação em Educação - PPGE-UFBA e a Universidade Paris XIII, Sorbonne, com base no Projeto "Boite a Jouer" desenvolvido em Paris (França), pelo grupo de estudos Experice, tendo como coordenador o Professor Gilles Brougère.
} 
- Revista de Iniciação à Docência, v. 5, n. 1, 2020 -

Dossiê Temático: Docência Universitária: contribuições da pesquisa Publicação: maio, 2020 - ISSN 2525-4332

Crê-se que essa opção foi a mais apropriada, por se tratar de uma pesquisa qualitativa que buscou "compreender as compreensões" (MACEDO, 2009) do olhar das estudantes do Curso de Pedagogia acerca do brincar das crianças e sobre os acontecimentos que ocorreram entre os sujeitos envolvidos na formação.

O desejo de desenvolver uma reflexão a respeito da experiência formativa sensível sobre a compreensão dos sentidos construídos pelas estudantes acerca do brincar, responde, por um lado, ao cuidado para não dissociarmos a profissionalidade docente do processo da produção de sua subjetividade; por outro lado, a intenção de desenvolver uma pesquisa fundamentada na hibridização dos princípios da fenomenologia e da história de vida pessoal e profissional, buscando tratar especificamente do professor em formação (PEREIRA, 2013).

Para Maffesoli (2005), o método compreensivo permite uma abordagem indutiva, que "nos faz entrar no próprio coração de nosso objeto de estudo, vibrar com suas emoções, participar de seus afetos, compreender o complexo" (p. 47), o nosso "conhecimento comum". Nos torna aptos para esse "eterno recomeço" da vida, ou seja, "a vida em sua eterna dimensão". Com isto, a sociologia que trabalha com "socialidade, imaginário ou cotidiano" não deve mais produzir "conteúdos", mas, sim, operar como "ponto de vista". Por isso, a fenomenologia é uma teoria aberta, que "não se permite enclausurar, quando muito é possível captar-lhe os contornos, descrever-lhe a forma, levantar as características essenciais" (MAFFESOLI, 2005, p. 47).

Assim, neste artigo, descreve-se dois momentos diferentes na produção de sentidos por meio das narrativas experipoiéticas. O primeiro, se constituiu em uma escola da rede municipal em Jequié-BA, com a realização da pesquisa Baú Brincante, na qual três alunas de Pedagogia aderiram voluntariamente à proposta da pesquisar: o brincar livre. $O$ segundo momento, a realização da escrita das narrativas com as estudantes de Pedagogia, durante as aulas da disciplina Ludicidade.

O Baú Brincante é compreendido como um artefato brincante, por ser um dispositivo mediador para a produção das brincadeiras espontâneas e da cultura lúdica de crianças no espaço escolar. São artefatos, objetos recicláveis manuseados pelas crianças enquanto brincam, ganhando novos sentidos, por aquelas que brincam, e que potencializam as experiências do brincar livre. Nessa pesquisa, as alunas observaram as crianças brincando livremente, por meio do Baú Brincante; após isso, elas realizaram suas narrativas experipoiéticas, escritas em forma de poemas.

A metodologia das narrativas experipoiéticas desenvolvida com as estudantes de Pedagogia, foi aplicada durante o $2^{\circ}$ semestre de 2018, durante as aulas da disciplina Ludicidade. A produção dessas narrativas se deu na forma de poemas, na qual elas 
- Revista de Iniciação à Docência, v. 5, n. 1, 2020 -

Dossiê Temático: Docência Universitária: contribuições da pesquisa

Publicação: maio, 2020 - ISSN 2525-4332

relatavam suas memórias e observações lúdicas, especificamente, a partir de suas recordações e compreensões acerca do brincar na época que eram crianças.

Para a feitura deste artigo foram selecionados - como recorte de interpretação - as narrativas de cinco estudantes. Dentre delas, a aluna com o codinome "Brilho" 5 que participou ativamente da pesquisa Baú Brincante, e as alunas JSS; L.A.; M.S.Q, que produziram suas narrativas experipoiética em forma de poesias e que cederam voluntariamente suas escritas poéticas para serem analisadas.

\section{Poética do brincar: experiências/sentidos acerca do lúdico das crianças de estudantes do curso Licenciatura em Pedagogia}

O lúdico ou a brincadeira, aqui, é compreendido como "um princípio formativo" (LEAL; D’ÁVILA, 2013) que possibilita a intuição, criatividade, espontaneidade e experiências de plenitudes, as quais preambulam uma consequente aprendizagem significativa e, assim, uma formação profissional efetiva. Por isso, escrever uma poesia, uma metáfora ou narrar uma experiência vivida, lúdica ou artística, oportuniza que as pessoas voltem a brincar com a imaginação, criando um clima de permissividade, liberdade, criatividade e de integração corpo-mente-espírito.

O estado poético pode ser produzido pela dança, pelo canto, pelo poema, que se constitui o tecido da nossa vida, como assegura Morin (2005, p. 36). Em consonância com a tese do citado autor, o futuro da poesia reside em sua própria fonte, pois "a poesia tem, certamente, ensaiado defender-se nos jogos, festas [...] ensaia resistir a prosa do mundo; em resumo a poesia é a estética, o amor o prazer, a participação e, no fundo, é a vida!" (MORIN, 2005, p. 59). Assim, "a poesia é a comunhão do prazer, do amor, do encontro do saber”, tal como fala Morin (2012, p. 35).

Foi nesta perspectiva que quatro alunas do curso participaram da proposta de produção de sentidos, de escrever com coração acerca da memória ou experiencias vividas com o brincar. Mas, como descrevem de forma poética uma cena brincadeira, quando olham para as brincadeiras das crianças? O que sentem? Quais os sentidos construídos por seus olhares, ao observarem o brincar das crianças?

Conforme Friedmann (2013), se o professor e o estudante desafiar-se a aprender uma língua que pouco conhece, ele terá a possibilidade de compreender e apreender as mensagens das diversas brincadeiras, "por meio da percepção das crianças, adentrando em suas paisagens e imagens, conhecendo suas culturas, lendo e tentando compreender seu vocabulário, sua gramática e significados" (FRIEDMANN, 2013, p. 46). A estudante Brilho, ao participar de uma atividade de observação de crianças brincando livremente, reafirma as palavras da autora supracitada, quando descreve:

\footnotetext{
${ }^{5} \mathrm{O}$ nome Brilho foi escolhido pela aluna. As demais estudantes não informaram, por isso foram colocados identificação de Letras iniciais do nome.
} 
- Revista de Iniciação à Docência, v. 5, n. 1, 2020 -

Dossiê Temático: Docência Universitária: contribuições da pesquisa Publicação: maio, 2020 - ISSN 2525-4332

A densidade que permeia o curso de pedagogia, devido a tantas demandas acadêmicas, muitas vezes, a nossa sensibilidade fica comprometida, o olhar sensível respaldado no que tange a intencionalidade do fazer pedagógico voltado para a ludicidade[...]. Mas no momento que temos a oportunidade de experimentar essa atividade relacionada para a criança (o baú brincante) nos aciona memórias da nossa própria infância, de todas as mudanças (sociais, econômicas e culturais) que passamos, reflete de maneira afetiva, política e também profissional para o que está sendo desenvolvido, nesse sentido, é o complemento para a nossa

formação humana, no qual é essencial para desconstruir em nós fatores que estão calcados a uma experiência escolar bastante tradicional e inexistente sobre o brincar livre.

(Diário de Bordo da Estudante - Maio,2017, cedidos à Pesquisadora, 2017)

Crê-se, pelas falas da discente Brilho, que a experiência do olhar sensível seja uma conquista para o estudante, pois ao falar e escrever sobre si, sobre sua história, estabelece sentido ao que foi e é vivido acerca das experiências com o brincar. Além disso, torna-se um caminho aberto para que o aluno possa produzir suas narrativas, com possibilidade de reconstruir e construir aprendizagens no percurso de sua formação (CARDOSO, 2008). Nessa arte, o estudante de Pedagogia "será ao mesmo tempo, objeto e sujeito da sua formação" permitindo uma retroalimentação, uma reflexão crítica a ponto de serem reformulados os conteúdos durante o processo de sua formação (NÓVOA, 2002, p. 22).

Neste contexto, ao ler o poema da estudante Brilho, conforme a Figura 2, percebese que sua narrativa revela para a ação de educar na perspectiva da escuta sensível, do senso compreensivo, da simpatia e da empatia. Como é descrito no poema a seguir:

Figura 2 - Narrativa Poética da Aluna Brilho

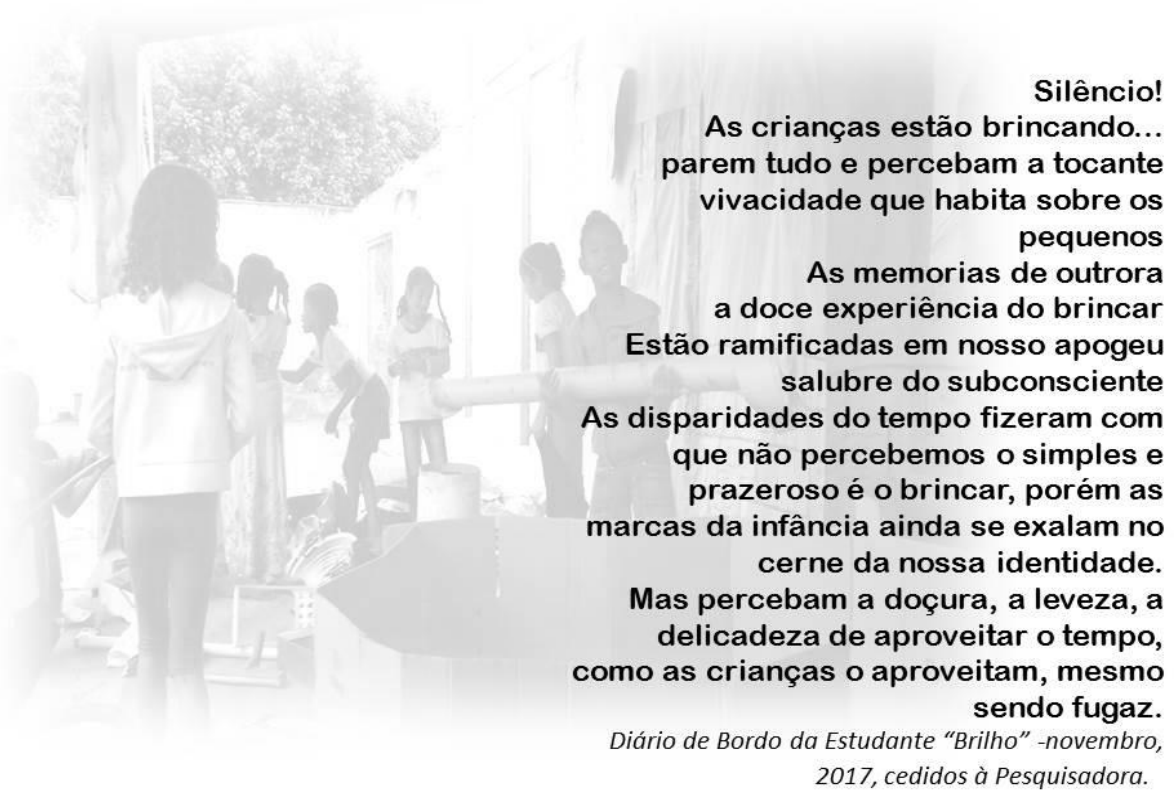

Maffesoli (1999) afirma que a experiência permite a vivência do sentimento, da emoção, do imaginário, do lúdico, em síntese, dos pequenos fatos da vida cotidiana. Momento em que o sujeito se autoriza a exercer a capacidade de sentir e pensar sob o 
- Revista de Iniciação à Docência, v. 5, n. 1, 2020 -

Dossiê Temático: Docência Universitária: contribuições da pesquisa Publicação: maio, 2020 - ISSN 2525-4332

olhar autopoiético, com o propósito de compreender e produzir outros sentidos às narrativas sobre o brincar da criança no espaço escolar.

Trata-se de abrir um espaço de voz e escuta que possibilita expandir o sentido aos olhos dos educandos "por corresponderem e alimentarem a sua demanda de formação [...] estimula investir esforços para divulgar e trazer à consciência de adultos e crianças a importância do brincar" (FORTUNA, 2012). Por meio dessa experiência sensível, eles têm a oportunidade de rever seus saberes sobre o brincar e construir outros novos, a partir do que observam nas crianças, nos seus jeitos de ser e estar no mundo.

Nessa experiência de narrativas poéticas cabem memórias e a ressignificação do imaginário do brincar de ontem no brincar de hoje, conforme pode-se perceber na Figura 3, considerando a narrativa da estudante MSQ, que descreve uma experiência de brincar de esconde-esconde como um momento de lazer e espontaneidade, ao mesmo tempo que aguça suas ressonâncias da sensibilidade num território de pertencimento.

Figura 3 - Narrativa Poética Esconde-Esconde.

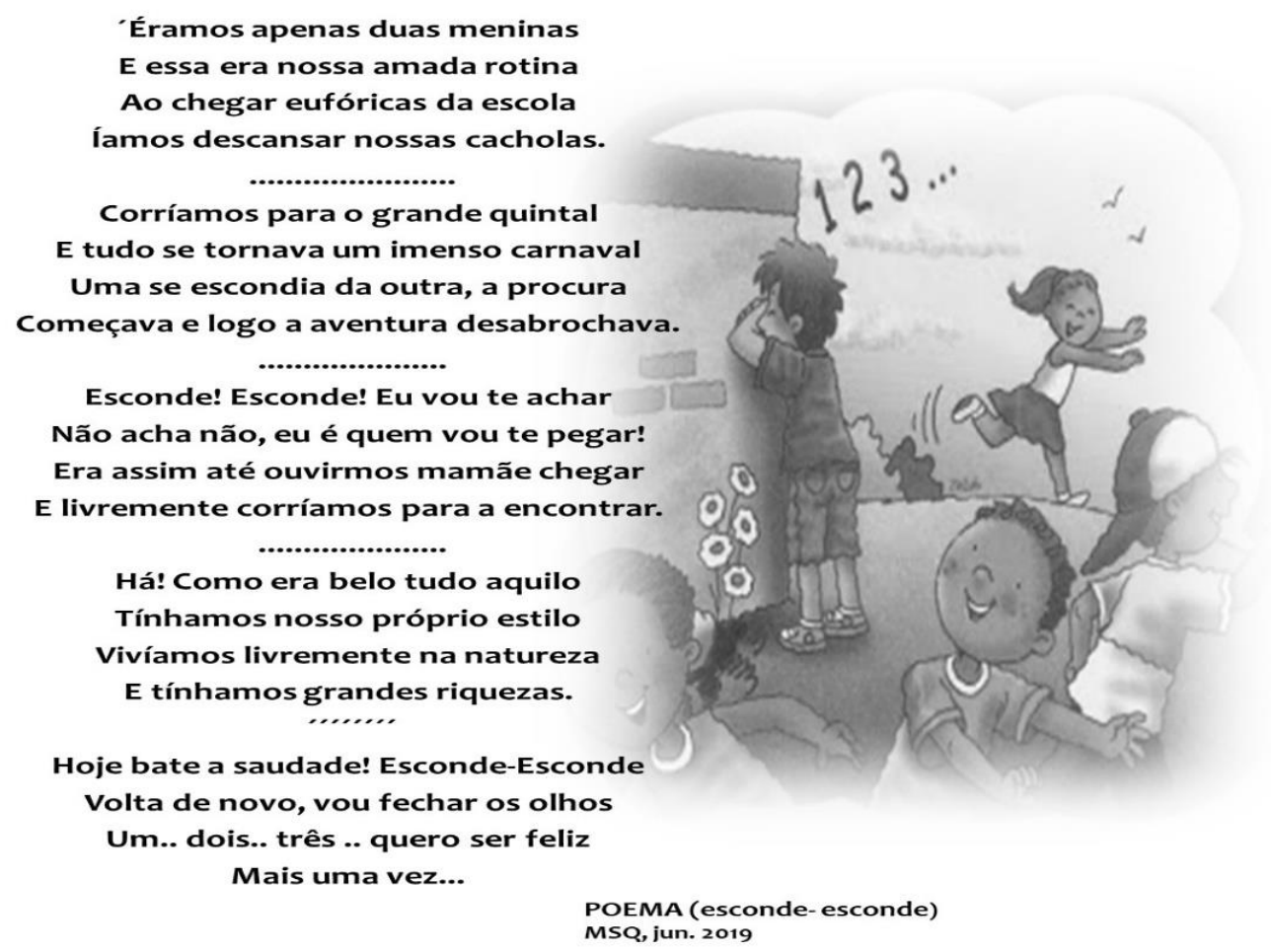

Ao ler o poema da estudante MSQ percebe-se que, para brincar, não há local ou tempos específicos. De acordo com Sutton-Smith (2017), a "variabilidade cultural - é a chave para brincadeira, e que, estruturalmente, a brincadeira é caracterizada por peculiaridade, redundância e flexibilidade" (p. 391). Por esse caminho, a estudante também construiu suas narrativas, redescobrindo o sentir, o pensar e o agir para/com o brincar das crianças, como uma potência poética e criativa, a partir da intuição, sensibilidade e criatividade. 
- Revista de Iniciação à Docência, v. 5, n. 1, 2020 -

Dossiê Temático: Docência Universitária: contribuições da pesquisa Publicação: maio, 2020 - ISSN 2525-4332

Ao oportunizar que as estudantes de Pedagogia narrem em forma de poesia seus conhecimentos lúdicos, compreende-se que elas conseguem de forma experimental metaforizar o que veem e sentem, quando relembram suas infâncias, observam ou contemplam o brincar de crianças nas escolas. Isto é, compreendemos que os estudantes, por meio da narrativa experipoiéticas, têm a oportunidade de redescobrir o sentir, pensar e criar, como uma potência poética e criativa, tal como aparece na Narrativa Poética Baleado, da estudante JSS (Figura 4).

Figura 4 - Narrativa Poética Baleado.

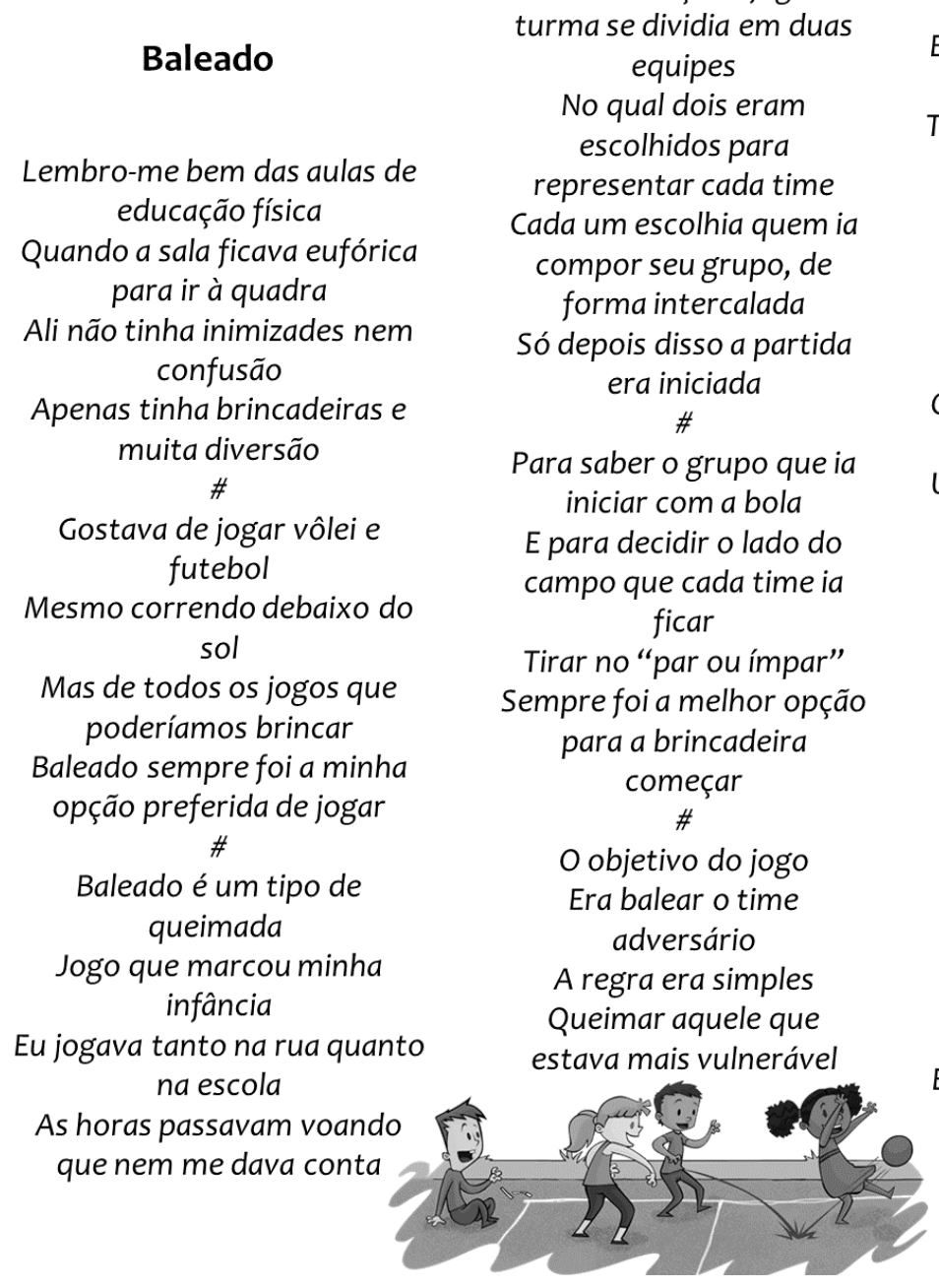

\section{Baleado}

o-me bem das aulas de o a sala ficava eufórica inha inimizades nem tinha brincadeiras e muita diversão de jogar vôlei e rendo debaixo do poderíamos brincar
podos aleado sempre foi a minha \# do é um tipo de que marcou minha tanto na rua quanto

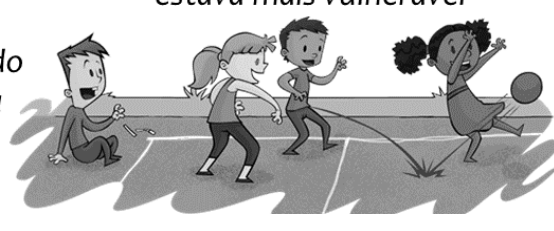

Para ser o time campeão Era necessário uma equipe forte e que tinha união

Trabalhar em equipe era o ponto forte do jogo

Ali aprendemos a defender e a proteger um ao outro

Não posso esquecer dos jogos intercolegiais

Quando a gente ia disputar com outras turmas

Utilizávamos a criatividade para criar a camisa da equipe

Momento tão esperado no tempo de criança

O foco nunca era jogar para ganhar

Pois aprendemos bem que o melhor da vida era estarmos

entre amigos e brincar

Esses sim são momentos inesquecíveis

Que nunca vão se apagar

Velha infância

Doce lembrança

É isso que o baleado representa para mim

No meu tempo de criança JSS, jun.2019

Na poesia descrita pela estudante JSS, o jogo Baleado é rememorado como a principal brincadeira do tempo de sua infância. O reconhecimento da cultura e da sensibilidade nas práticas profissionais pode ajudar na valorização dos professores a partir da identificação e do resgate do que eles têm de precioso dentro de si, o que, por sua vez, pode constituir-se em caminho para uma nova profissionalidade ressignificada. Assim, o caminho possível para que isto possa acontecer é o olhar para as culturas escolares, que 
- Revista de Iniciação à Docência, v. 5, n. 1, 2020 -

Dossiê Temático: Docência Universitária: contribuições da pesquisa

Publicação: maio, 2020 - ISSN 2525-4332

permite discutir a ambiência social - ética e estética de uma sociedade marcada no tempo e no espaço (MAFFESOLI, 1999).

A criatividade e a autoria são estruturantes de uma ação educativa lúdica (D’ÁVILA,2012). Por isso, uma experiência sensível implica uma articulação entre atividade, sensibilidade, afetividade e ideação. Esses elementos podem ser percebidos na Narrativa Poética Brincadeira de Criança, da estudante L.A, apresentada na Figura 5.

Figura 5 - Narrativa Poética Brincadeira de Criança.

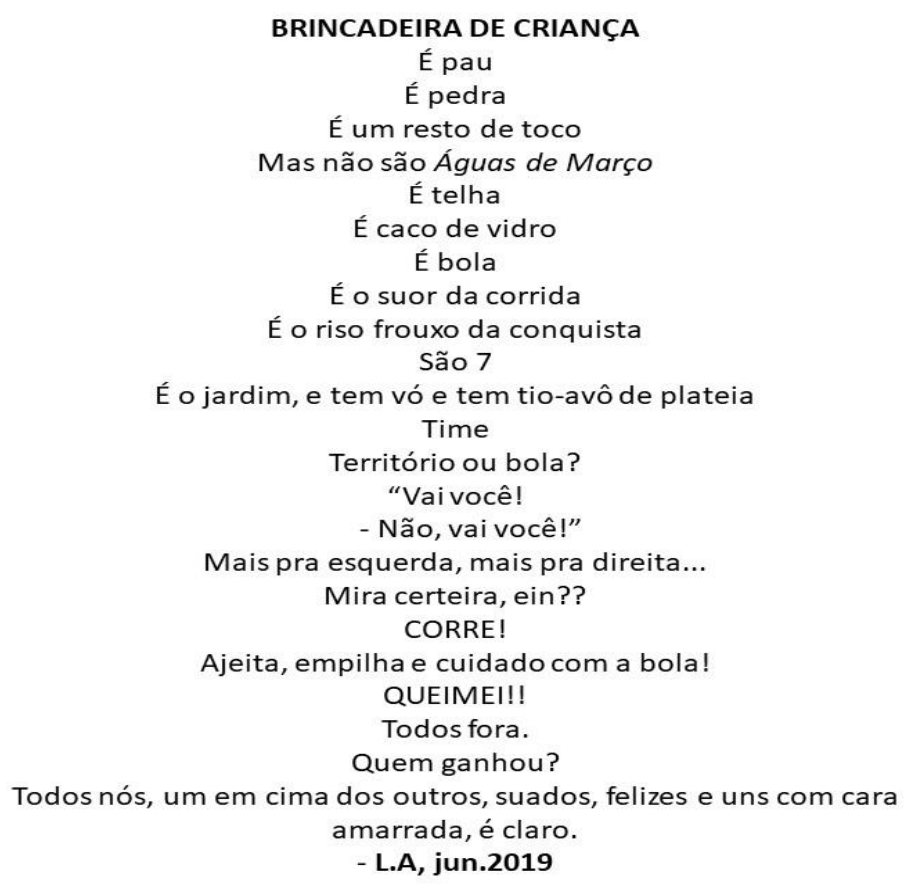

Ao criar sua poesia, a aluna L.A. nomeia e inventa continuamente, oferece o colorido de uma arte, mostra as linhas e as amarrações de uma teia, configurando, confeccionando e tecendo os fios, desenhos, traços e retratos insonháveis e singulares que até então são invisíveis (CARDOSO, 2013).

Segundo Mafessoli (1988), o desafio da experiência é o reencantamento do mundo a partir de seu pensamento social, o que ele denomina de socialidade ${ }^{6}$. "Cumpre-nos voltar os olhos para esta vida de todo dia que, de modo caótico e aleatório, no tédio e na exuberância, prossegue seu caminho de modo obstinado e um tanto incompreensível" (MAFESSOLI, 1988, p. 11), o que significa mostrar como a vida cotidiana se exprime de forma fragmentada e totalmente plural, identificando as pistas que ela nos abre e as várias máscaras com as quais se adorna para prosseguir.

\footnotetext{
${ }^{6}$ Socialidade é entendida como as minúsculas situações da vida cotidiana de não finalismo e de solidariedade orgânica. Reside num misto de sentimentos, paixões, imagens e diferenças que incitam a relativizar as certezas estabelecidas e remete a uma multiplicidade de experiências coletivas. Exprime a irreprimível e misteriosa vontade de viver de toda a existência individual e social (MAFFESOLI, 1988, p.8; p. 12).
} 
- Revista de Iniciação à Docência, v. 5, n. 1, 2020 -

Dossiê Temático: Docência Universitária: contribuições da pesquisa Publicação: maio, 2020 - ISSN 2525-4332

Portanto, o trabalho na docência universitária, a nosso ver, necessita abrir os olhos do coração, pois acredita-se que uma prática educativa sensível, por meio de metáforas criativas e narrativas poéticas sobre o brincar, possibilita um caminho aberto de experiência mais amorosa por parte dos adultos. Corroborando ao pensamento de Brito e Cunha (2008) que "a docência é, para além da sala de aula, um ato político, com intencionalidades, com práticas que envolvem o pensar na formação do outro sujeito e, dessa forma, é transversalizada pelo ensino" (p. 168). Daí a importância de aprender a contemplar e a reconhecer todos os sentimentos, pensamentos, sensação e intuição. Como afirma Maffesoli: "olhar significa também tomar conta de cuidar, de zelar. Por isso é o que significa ver. Não ver através das lunetas ideológicas, de lentes deformantes, mas levar em conta aquilo que se dá a ver"' (MAFFESOLI, 2009, p. 96).

\section{Concluindo provisoriamente}

Os cursos de formação precisam pensar e criar possibilidades de "uma experiência de linguagem, uma experiência de pensamento, e uma experiência sensível, emocional, uma experiência em que está em jogo nossa sensibilidade, isso que chamamos sentimentos" (LARROSA BONDIA, 2011, p. 10, grifo do autor). Ou seja, a compreensão e a sensibilidade estão intimamente ligadas, visto fazerem parte do terreno fértil de religação que une corpo, mente e o espírito; uma conexão entre pensamento, sentimento, aprendizagem e vida, "dando o devido destaque aos saberes das experiências vividas, lembrando que cada indivíduo traz consigo a singularidade de suas experiências, de suas vidas" (MORIN, 2012, p. 31).

Considero que é com base nessa experiência do olhar que a profissionalidade se origina, sobretudo, na produção de sentidos. Um olhar para si e para a ação profissional docente, o que inclui a cultura escolar, dentre as quais um destaque à cultura lúdica. É importante ressaltar ainda que, as experiências sensíveis com o brincar, a poesia, a metáfora são cruciais para o bem-estar e para a felicidade humana, seja qual for a etapa da vida. A liberdade está dentro do corpo do ser e não é diferente com os professores. Deixálos perceber, dar condição para tal, é acreditar na transformação e principalmente na construção do novo perfil da profissionalidade docente.

\section{Referências}

ABBAGNANO, N. Dicionário de Filosofia. Tradução de Alfredo Bosi. São Paulo/SP: Martins Fontes, 2000.

BACELAR, J. Poesia visual. Biblioteca on-line de ciências da comunicação. Portugal, 2001. Disponível em: <http://www.bocc.ubi.pt/pag/bacelar-jorge-poesia-visual.pdf $>$. Acesso em: 17 out. 2017.

BRASIL. Ministério da Educação. Conselho Nacional de Educação. Resolução CNE/CP n. 02/2015, de $1^{\circ}$ de julho de 2015. Fixa Diretrizes Curriculares Nacionais para a formação inicial em nível superior (cursos de licenciatura, cursos de formação pedagógica para graduados e cursos de segunda licenciatura). 
- Revista de Iniciação à Docência, v. 5, n. 1, 2020 -

Dossiê Temático: Docência Universitária: contribuições da pesquisa Publicação: maio, 2020 - ISSN 2525-4332

BRITO, T. T. R; CUNHA, A. M. O. A docência no Instituto de Biologia da Universidade Federal de Uberlândia: percorrendo caminhos e encontrando representações. Práxis Educacional, v. 4, n. 5, 2008, p. 151-172.

CARDOSO, M. C. Catadoras do brincar: o olhar sensível das professoras acerca do brincar livre no ensino fundamental I e suas ressonâncias para a profissionalidade docente. 2018. 212f. Tese (Doutorado em Educação). Universidade Federal da Bahia. Faculdade de Educação, Salvador/BA, 2018.

. Baú de memórias: representações de ludicidade de professores de educação infantil. 2008. 170f. Dissertação (Mestrado em Educação) - Universidade Federal da Bahia Programa Faculdade de educação, Salvador/BA, 2008.

. Formação, saberes e profissionalização das docentes da casinha do sol/UESB: fios de reflexões em desafios pensantes. Saberes em Perspec. Jequié/BA, v. 3, n. 5, p. 57-75, 2013.

D’ÁVILA, C. M. Didática: a arte de formar professores no contexto universitário. In:

.; VEIGA, I. P. Didática e docência na educação superior. Implicações para a formação de professores. Campinas/SP: Editora Papirus, 2012, p. 6-19.

.; FERREIRA, L. G. Concepções pedagógicas na educação superior: abordagem ontem e hoje. In: D’ÁVILA, C. M.; MADEIRA, A.V. (Org.). Ateliê didático: uma abordagem criativa na formação continuada de docentes universitários. Salvador/BA: EduFBA, 2018.

DEWEY, J. Arte como Experiência. São Paulo/SP: Martins Fonte, 2010.

FORTUNA, T. R. Descobertas sobre a formação lúdica docente. Pátio Educação Infantil, Porto Alegre/RS, ano 10, n. 31, p. 8-11, abr./jun. 2012. ISSN 1677-3721.

FREITAS, M. B. O brincar e a ludicidade como saberes da profissionalidade docente na educação infantil: contributos e paradoxos da formação continuada na escola. 2014. Tese (Doutorado em Educação) - Universidade Federal de Pernambuco, Ceará. Programa de Pós-Graduação em Educação, Pernambuco/CE, 2014.

FRIEDMANN, A. Linguagens e Culturas Infantis. São Paulo/SP: Cortez, 2013.

GALEFFI, D. A. Educação estética como atitude sensível transdisciplinar: o aprender a ser o que se é propriamente. Em Aberto, Brasília/DF, v. 21, n. 77, 2007, p. 97-111.

LARROSA BONDIA, J. L. Experiência e alteridade em Educação. Reflexão e Ação, v. 19, n. 2, 2011, p. 4-27.

LEAL, L. A.; D’ÁVILA, C.M. A ludicidade como princípio formativo. Interfaces Científicas, Educação, Aracaju/SE, v. 1, 2, p. 41-52, fev. 2013.

LUCKESI, C. C. Ludicidade e formação do educador. Entreideias, Salvador/BA, v. 3, n. 2, 2014, p. 13-23.

MACEDO, R. S. Outras luzes: um rigor intercrítico para uma etnopesquisa política. In: GALEFFI; D. PIMENTEL, Á. Um rigor outro sobre a qualidade na pesquisa qualitativa: educação e ciências humanas. Salvador/BA: EDUFBA, 2009.

MAFFESOLI, M. O conhecimento comum: compêndio de sociologia compreensiva. São Paulo/SP: Brasiliense, 1988. 
- Revista de Iniciação à Docência, v. 5, n. 1, 2020 -

Dossiê Temático: Docência Universitária: contribuições da pesquisa Publicação: maio, 2020 - ISSN 2525-4332

. No fundo das aparências. 2.ed. Petrópolis/RJ: Vozes, 1999.

. Elogio da razão sensível. $3^{\mathrm{a}}$ ed. Petrópolis/RJ: Vozes, 2005.

. A República dos Bons Sentimentos. São Paulo/SP, Iluminuras: Itaú Cultural, 2009.

.; ICLE, G. Pesquisa como conhecimento compartilhado: uma entrevista com

Michel Maffesoli. Educ. Real., Porto Alegre/RS, v. 36, n. 2, 2011, p. 521-532.

MORIN, E. Amor, poesia, sabedoria. Rio de Janeiro/RJ: Bertrand do Brasil, 2005.

MORIN, E. Os saberes necessários à educação do presente. In: MORAES, M. C.; ALMEIDA, M. C. (Orgs). Os Sete Saberes Necessários à Educação do Presente: por uma educação transformadora. Rio de Janeiro/RJ: Wak Editora, 2012.

NÓVOA, A. Diz-me como ensinas, dir-te-ei quem és e vice e versa. In: FAZENDA, I. C. A. (Org.). A Pesquisa em Educação e as Transformações do Conhecimento. Campinas/SP: Papirus, 1997.

. Formação de Professores e Trabalho Pedagógico. Lisboa/Portugal: EDUCA 2002.

PEREIRA, M. V. Estética da professoralidade: um estudo crítico sobre a formação do professor. Santa Maria/RS: Ed. UFSM, 2013.

PIMENTA, S. G. Epistemologia da prática: ressignificando a didática. In: MONTEIRO, B. S.; PIMENTA, S. G. Escritos sobre didática, filosofia e formação de educadores. Cuiabá/MT: EdUFMT, 2013.

.; ANASTASIOU, L. G. C. Docência no Ensino Superior. São Paulo/SP: Cortez, 2014.

SANTOS, B. S. Um discurso sobre as ciências. São Paulo/SP: Cortez, 2003.

SUTTON-SMITH, B. A ambiguidade da brincadeira. Revisão Técnica da Tradução de Tânia Ramos Fortuna. Petrópolis/RJ: Vozes, 2017. 